\title{
La flora i la fauna centreeuropees dels Contes dels germans Grimm i llur correspondència a la traducció al català de Carles Riba
}

\author{
Macià Riutort i Riutort \\ Universitat Rovira i Virgili \\ macia.riutort@urv.cat
}

\begin{abstract}
RESUM
L'objectiu originari del present treball era estudiar com l'hel-lenista, traductor i escriptor Carles Riba havia escomès la traducció al català dels noms de plantes $i$ animals que apareixen a la versió alemanya dels Contes dels germans Grimm. L'interès del treball derivava de la constatació que Carles Riba havia dut a terme la seva traducció dels contes grimmians quan encara no existien grans obres lexicogràfiques bilingües i quan la llengua encara no havia aconseguit assolir la consolidació del seu estàndard literari, en la qual va cooperar tant Riba amb la seva tasca. Al llarg de la realització d'aquest treball, el seu autor ha constatat, a més a més, que els noms de plantes $i$ animals en els Contes dels germans Grimm apareixen distribuïts en estrats estilistics diferents, de manera que l'estudi de la flora i la fauna a la versió alemanya dels contes es pot constituir en un mètode concloent amb vista a datar el moment de la creació del conte i a localitzar el lloc de redacció, així com amb vista a situar l'origen del conte en un entorn popular o culte.
\end{abstract}

PARAUles CLAU

Grimm, contes, rondalles, Carles Riba, traducció, fauna, flora 


\begin{abstract}
The original objective of the present work was to study how the Hellenist translator and writer, Carles Riba, translated into Catalan the names of plants and animals which appear in the Tales of the Brothers Grimm. This interest in his work arose from the realization that the translation was done at a time when there were no great bilingual dictionaries of Catalan nor had the Catalan language reached the definitive standard it has today. A thorough analysis of the work proved that the study of the names of plants and animals in the Tales of the Brothers Grimm can be distributed according to different cultural strata. Thus, the study of the flora and fauna in those Tales can offer definite clues regarding the date and place of the creation of the Tale. It can also establish if it was created within a popular environment or, alternatively, within an educated one.
\end{abstract}

\title{
KEYWORDS
}

Grimm, fairy tales, Carles Riba, translation, fauna, flora 
La flora i la fauna centreeuropees dels Contes dels germans Grimm...

\section{Nota preliminar}

Tota consideració que es faci sobre el tema que ens ocupa ha de tenir, forçosament, un caràcter provisori, ja que es veu condicionat per l'existència de variables desconegudes que, fins que no es resolguin, no permetran aclarir totalment l'objecte del nostre treball.

Aquestes variables són:

I) els diccionaris de què disposava Riba per escometre la seva tasca com a traductor,

2) la versió alemanya dels Contes dels germans Grimm que tenia,

3) les enciclopèdies de què disposava, i, finalment,

4) quines altres traduccions (franceses, italianes o castellanes) podia tenir i emprar com a guia per resoldre els problemes translaticis que se li plantegessin al llarg de la seva feina.

A banda d'aquesta consideració preliminar, també vull indicar d'antuvi que el meu estudi se circumscriu als dos volums de contes titulats Contes d'infants i de la llar, que foren editats versemblantment el I9I9 i el I92 I ${ }^{\mathrm{I}}$ per l'Editorial Catalana a la Col-lecció Literària (amb els números I5 i 38) i les Rondalles de Grimm, il-lustrades per Arthur Rackham, una tria de contes dels germans Grimm que fou publicada per l'Editorial Joventut el I935.

\section{Delimitació de la recerca}

Originàriament, l'objecte d'aquest treball pretenia ésser un estudi sobre com en Carles Riba havia resolt el problema dels noms d'animals i de plantes en la seva traducció dels Contes dels germans Grimm, en uns moments en què el català encara no disposava d'un estàndard fixat en aquest punt i tenint en compte que l'entorn geogràfic dels germans Grimm i llurs contes havia de comportar una especificat centreeuropea dels noms dels animals i plantes que hi apareixen, que, per força, havia de plantejar problemes lèxics a Riba.

Des d'aquesta perspectiva, podem classificar la flora i fauna grimmianes en quatre grups:

I) flora i fauna específiques del centre d'Europa,

2) flora i fauna comunes a la Mediterrània,

3) flora i fauna comunes a la Mediterrània però d'escassa presència social en el nostre entorn, i, finalment,

4) flora i fauna amb connotacions diferents en alemany i en català o amb un ús metafòric diferent.

I. En el catàleg del Llegat Vidal-Capmany de la URV, els dos volums hi figuren com a publicats el I9I9 i el I92I. Els llibres foren impresos sense indicació de l'any d'impressió. 


\subsection{Flora i fauna específiques del centre d'Europa}

Un cop iniciada la recerca de la terminologia faunística i botànica alemanyes en els Contes dels germans Grimm, es constata amb enorme sorpresa la poca presència de la flora i fauna específiques del centre d'Europa en els Contes.

Una altra sorpresa és que les referències a la fauna i la flora, almenys en els contes objecte del present estudi, són extremadament generals, ço és, inespecífiques: els contes defugen la terminologia específica i recorren a l'ús abundós, per contra, de termes genèrics com ara prat, bosc, arbre, arbust/arbúcia/espessorall, herba, flor, bèstia/animal. Aquest fet hi està tan estès que ens permet formular la següent hipòtesi de treball per explicar-lo:

Els contes neixen — contra tot pronòstic_- en un entorn urbà, no rural. Un entorn urbà explicaria perfectament, al meu entendre, la poca especificitat a l'hora d'anomenar la flora i la fauna. Considerem el cas següent: en una narració feta per un pagès, tendirà a explicar que un fet s'esdevé vora un roure i no pas vora un arbre i que aquest mateix fet va passar quan cantava una tàpara i no pas simplement un ocellet. Per contra, l'habitant d'una ciutat o narrador lletraferit, però poc avesat al camp, contarà que un cert fet s'esdevé vora un arbre i no pas vora un roure i que passa quan cantava un ocellet i no pas una tàpara. Aquesta situació és, en definitiva, la mateixa que ens caracteritza actualment a nosaltres mateixos, que només som capaços de denominar les plantes i els animals que formen part de la nostra vida quotidiana, i, per tant, en una hipotètica narració que construíssim, només els inclouríem a ells. ${ }^{2}$ Jutjo, per tant, que l'absència d'una terminologia botànica i faunística específiques en els contes dels germans Grimm s'ha d'entendre apriorísticament com un indicador de l'origen urbà —no rural — de llurs autors o, alternativament, de l'origen culte/lletraferit de l'autor. Per determinar si es tracta en definitiva d'un autor no rural o d'un autor culte/lletraferit, cal recórrer a un seguit d'altres elements.

Però encara goso anar més lluny: observo aquí que fruits com ara la pruna, la cirera i la pera són fruits d'arbres mediterranis aclimatats d'antic en el territori lingüístic de l'alemany. Tanmateix, i malgrat l'enorme antiguitat de llur aclimatació, la presència als contes hi és molt escassa. Així, assenyalo que no hi ha ni una rondalla grimmiana on surtin esmentades les prunes o les pruneres, i només quatre contes on s'esmentin les peres:

\footnotetext{
2. Al costat d'aquests termes n'hi ha un seguit que jo denomino paraarcaismes. En el nostre cas, es tracta de termes botànics i faunístics que continuen tenint una certa presència en la llengua quotidiana de qualsevol parlant posseïdor d'una educació mitjana, sense que aquest parlant sàpiga realment de quina espècie animal o botànica està parlant. A tall d'exemple: en un experiment fet el $1997 \mathrm{amb} 30$ alumnes, tots varen afirmar que coneixien encara mots com civada, ordi o blat. Alhora, però, no foren pas capaços de reconèixer-los, com també es van mostrar incapaços de distingir el cant del rossinyol del del pinsà o del de la calàndria, i això que eren estudiants de filologia i que precisament el cant d'aquests ocells té una certa presència en la literatura, especialment la del segle XIX.
} 
«La Cendrosa / Aschenputtel», «Die Gänsehirtin am Brunnen / L'ocatera vora la font» i dos contes que ell no va traduir: «Das Mädchen ohne Hände» $\mathbf{i}$ «Der Krautesel». Malgrat que l'observació que faré no s'adiu ben bé al tema de la contribució a aquest simposi, considero que, tanmateix, sí que és oportú fer-la: crec que la presència de la pera o la cirera en els contes grimmians és tan escassa que la presència d'aquests fruits s'ha de veure com un indicador de l'origen últim no alemany dels contes en els quals apareixen. D'aquí n'extrec la següent conclusió que presento com a hipòtesi per demostrar: la presència de la botànica i la fauna no tradicionals alemanyes als contes grimmians es poden utilitzar com a pedres de toc per comprovar el possible origen autòcton o forà dels contes.

El cavall tenia, en les societats occidentals anteriors a la invenció de la ferrovia i l'automòbil, una forta implantació, ja que condicionava la mobilitat en tots els sentits. Per això, hauríem de creure que els Contes dels germans Grimm haurien de reflectir aquest fet oferint una rica presència de terminologia diferenciada al voltant del cavall. No és pas així, si més no en els contes que són objecte del present estudi: en els contes només hi solem trobar referències molt vagues als cavalls, i la diferenciació terminològica, les poquíssimes vegades que es fa, es basa en el color de la pell o del pelatge i, en alguna ocasió, en la qualitat del cavall (tipus: Pferd, Ross, Gaul). Per aquesta raó, quan topem amb el que aparentment és una excepció, com ara la que constatem al conte «Der Eisenhans / En Janferrís», no podem fer res més que pensar que el conte representa una nota discordant en el conjunt dels contes i que ho és perquè pertany a un estrat estilístic i, per tant, temporal, diferent del de la resta de contes. El gust per una terminologia diferenciada al voltant del cavall és, al meu entendre, molt pròpia del romanticisme alemany. Aquest conte, amb el seu gust per una gran diferenciació terminològica dels cavalls basada en el color de llur pell, per tant, se'ns revela, per aquest tret estilístic, com un conte sorgit, almenys en la seva forma definitiva, en l'època del romanticisme alemany. ${ }^{3}$

3. Carles Riba ens ofereix les equivalències següents: ein Pferd / un cavall; ein Roß / un corser; ein stolzer Fuchs / un superb cavall roig; ein Schimmel / un cavall blanc; ein Rappen / un cavall negre. No deixo passar l'ocasió de comentar que considero l'equivalència ein stolzer Fuchs / un superb cavall roig estilísticament millor que l'esperable *un superb cavall alatzà, sobretot perquè mai de la vida no he sentit ningú que, parlant català, parlés d'un cavall alatzà. Tanmateix, hem d'esmentar que en el conte «Der treue Johannes / El fidel Joan», Riba tradueix ein prächtiger fuchsroter Gaul de l'original per un magnífic cavall color roig de guineu. La diferent traducció (un cavall roig / un cavall color roig de guineu) mostra, al meu entendre, un Riba no gaire familiaritzat $\mathrm{amb}$ aquestes diferenciacions terminològiques equines basades en el color del pelatge dels animals. A banda, hi ha també el mot Gaul, que Riba tradueix aquí per cavall, mentre que en el conte «Die Gänsemagd / L'ocatera» el traduirà, més adequadament, per ròssa (i, també en aquest mateix conte, hi traduirà el sinònim auf das schlechte Ross per damunt del mal rossí) un cop i pallanca en una altra ocasió (ein Gaulskopf / un cap de pallanca): cavall, ròssa, rossí, pallanca representen als meus ulls un exemple de com Riba va fent-se lentament amb un vocabulari, al qual s'haurà primerament d'avesar, amb el qual posteriorment disposarà d'una llengua rica i mal-leable. 
Un dels pocs termes que he trobat als contes alemanys que Carles Riba va traduir és el de Hornisse, designació alemanya de l'insecte Vespa crabro, que no es dóna pas entre nosaltres. Aquest insecte apareix esmentat al conte «Der Zaunkönig und der Bär / El reietó i l'ós». El límit meridional europeu d'extensió d'aquest insecte és el Rosselló, on rep el nom de fosseró, que és el mot amb què se l'hauria de designar a l'estàndard científic català. Riba, als Contes dels germans Grimm, tradueix el mot alemany amb el mot català abegot:

Der Zaunkönig aber berief alles, was in der Luft fliegt; nicht allein die Vögel groß und klein, sondern auch die Mücken, Hornissen, Bienen und Fliegen mußten herbei / El reietó, per la seva banda, crida tot allò que vola per l'aire: no solament els ocells petits i grossos, sinó també els mosquits, els abegots, les abelles i les mosques van haver d'acudir.

Riba va interpretar Hornisse com el mascle de l'abella, però una Hornisse no és cap abella, sinó una vespa de picada terrible. L'abegot, per contra, no té ni tan sols fibló: no pot picar. La traducció de Riba potser s'inspira en el diccionari Tolhausen, que dóna, correctament, com a equivalents castellans de Hornisse els mots 'avispón, abejón'. Doncs bé, abejón també és sinònim, en castellà, de zángano, i zángano és l'abegot català. Vet ací com, al meu parer, Riba va arribar a l'equivalència (incorrecta) Hornisse: abegot.

Tanmateix, hi ha pocs casos més que es podrien encabir en aquest apartat. Així, per exemple, en el conte «Der gläserne Sarg / El taüt de cristall» hi apareix el terme Leibzelter, que Carles Riba tradueix amb el terme haca. Leibzelter o Leibzeltner no designa un cavall de raça petita, com són els cavalls anglesos de Hack o Hackney, sinó el cavall amblador (Zelter, Zeltner) personal (Leib-) de nobles, senyors en general i, sobretot, de dames i clergues, que rep la seva designació d'ésser un cavall que ambla: el Zelt és uns dels aires - forma de caminar o avançar-d'un cavall, i un Zelter no és res més que un cavall amblador, un cavall que ambla o que va al pas. Personalment, crec que la traducció de Riba s'ha de qualificar, malgrat tot, de correcta, ja que, si el terme Leibzelter sol connotar un cavall d'un noble, un clergue o una dona, això és també el que sol connotar el terme haca en català, encara que l'haca sigui un cavall de mida petita.

Hi ha alguns casos en els quals el gènere i l'espècie no són importants amb vista a la traducció —encara que sí per a l'il-lustrador dels contes-. Així, en el conte «Schneeweisschen und Rosenrot / Blancaneu i Rosavermella», l'única traducció correcta de l'alemany Sommervögel és la que ofereix Riba: papallones, i poc importa de quin gènere i espècies són. De fet, cal contemplar aquest terme com un terme genèric que designa qualsevol insecte volador que tingui una determinada forma. Aquest mateix exemple s'ha d'esmentar perquè Riba va traduir el mot correctament evitant de caure en el parany de traduir-lo — com solen fer els novells de la llengua 
alemanya- per «ocells d'estiu» — que és el que vol dir el mot alemany en sentit literal-.

Un problema que aquí només vull esbossar és el que constitueix el fet que l'espècie o la subespècie ibèrica sovint és diferent de l'espècie o subespècie equivalent mesoeuropea: això vol dir que el llop alemany i el llop ibèric, per bé que pertanyin al mateix gènere i espècie, constitueixen dues subespècies diferents. Aquest fet no és rellevant per si mateix per al traductor, però sí per a l'il-lustrador dels contes perquè les subespècies i les espècies solen distingir-se per la forma i, en el cas dels animals, pel color del pelatge. Aquest punt enceta tota una altra problemàtica, la de les espècies subjacents a les il-lustracions que acompanyen els contes grimmians, i que aquí no es pot tractar per no ultrapassar els límits lògics del treball.

\subsection{Flora i fauna comunes al centre d'Europa i a la Mediterrània}

Carles Riba, com ens podem imaginar, tradueix sempre bé la terminologia alemanya quan es tracta de fauna i flora comunes al centre d'Europa i a la Mediterrània.

Tanmateix, es poden constatar, ça i lla, equivalències errònies que no sempre són fàcils d'explicar. Així, en el conte «Die Gänsehirtin am Brunnen / L'ocatera vora la font», Riba tradueix l'alemany Brennnesseln 'ortigues' amb el mot escardots, que hem d'entendre com a simple variant de cards. Al meu entendre, no hi ha res que justifiqui la substitució del mot ortiga pel mot escardot tret que Carles Riba, en escometre la seva traducció, cregués erròniament que el mot ortiga era un castellanisme i que el seu equivalent autèntic català era escardot. Aquesta és l'explicació que jo em dono, encara que no es pugui basar en la informació dels diccionaris de català consultats.

Un altre cas que també s'arrenglera aquí i que, per això mateix, cal comentar és el de la traducció de l'alemany Eiche o Eichbaum 'roure' per alzina. És el cas dels contes «Das tapfere Schneiderlein / El sastrinyol valent» o «Der junge Riese / El gegant jove». Quina podia ser la motivació ribiana per a aquest canvi és problemàtic d'escatir perquè roure i alzina són, fet i fet, dos arbres del nostre entorn, encara que l'alzina sigui més comuna que no pas el roure. És possible que sigui aquesta darrera característica la que empenyés Riba a canviar el roure original per l'alzina: la considerava més nostrada.

Esmento, ja per acabar, dos exemples més: en el conte «Die drei Glückskinder / Els tres minyons de la sort», Riba tradueix el mot alemany Mäuse 'ratolins' per rates. Atès que tant les rates com els ratolins són animals del nostre entorn i atès que no hi ha cap problema a l'hora de distingir-los, el canvi terminològic de Riba no es pot deure a la descurança o al desconeixement lingüístic, sinó que havia d'obeir a un propòsit de l'autor que, tanmateix, no he estat pas capaç de revelar. El mateix s'esdevé en el conte 
«Die zwei Brüder / Els dos germans». Aquí, el Hummel 'borinot' alemany és substituït per un enigmàtic vespot català, sense que pugui aconseguir endevinar què va poder empènyer Riba a fer aquesta substitució.

\subsection{Flora i fauna comunes a la Mediterrània però d'escassa pre- sència social en el nostre entorn}

Durant la redacció d'aquest treball, em vaig adonar que hi havia tota una sèrie de designacions alemanyes de plantes o animals que, malgrat que també existeixen en l'entorn del català, sembla que van resultar problemàtiques d'alguna manera per a Riba i que el motiu de la dificultat s'havia de cercar, d'una banda, en la poca implantació d'aquestes plantes i animals en el nostre col-lectiu lingüístic, fins al punt que es poden considerar plantes i animals desconeguts, o, si més no, ho devien ser fa un segle. Aquest fet afecta molt més el món de la botànica que no pas el dels animals. D'altra banda, és possible que una part de la dificultat d'aquests mots s'hagués de cercar en els diccionaris de què disposava Riba per dur a terme la tasca de traducció, i sobre els quals parlaré adés.

A tall d'exemple del que dic aquí, esmento ara el genèric alemany Beere. Beere significa 'baia' i, en alemany, igual que en català, té dos significats força divergents: un significat popular i un significat científic, botànic. Aquests dos significats no coincideixen sempre, de manera que el parlant pot entendre com a Beere - com a baia—, un fruit que botànicament no ho és i al revés. Així, les maduixes, en alemany es diuen Erdbeeren, és a dir, baies de terra, i aquesta designació ja ens revela que aquest fruit és sentit com una baia pel parlant alemany, mentre que un fruit com ara Tomate, la tomata, que botànicament és una baia, no ho és pas per al sentiment popular.

En un món com és el centreeuropeu i, de manera especial, en el món centreeuropeu anterior a la globalització, l'accés a la fruita estava molt restringit. L'única fruita popular realment existent des de sempre era la poma. Qualssevol altres fruits s'hi han de veure com una aportació del sud, per bé que alguns siguin antics, com ara la prunera i la perera, fruits d'arbres que aconseguiren aclimatar-se arreu del territori lingüístic alemany després que hi haguessin arribat des de la Mediterrània, possiblement a partir de l'època carolíngia. Tanmateix, i a diferència de les pomes, les prunes i les peres - a les quals encara podríem afegir les cireres-, no són pas fruits que es conservin gaire temps, la qual cosa fa que siguin una fruita que s'ha i s'havia de collir i menjar. El seu consum quedava limitat, per tant, a la tardor, quan n'era la collita. Per tot això, les baies havien tingut de sempre al centre d'Europa un pes alimentari i un paper social molt grans semblants al de la fruita en general a la Mediterrània. Així, per posar un exemple, l'aportació de vitamina C, que nosaltres hem fet 
tradicionalment a través de fruites com ara els cítrics, al centre d'Europa es feia a través de baies com ara les baies de l'arç groc, el Sanddorn alemany.

La traducció del mot genèric Beere no hauria de ser cap problema per a un traductor, ni d'ara, ni de fa cent anys, atès el testimoni dels diccionaris bilingües disponibles aleshores. I, tanmateix, ho és. Riba tradueix el genèric alemany Beere i la seva variant Waldbeere no pas per baia, com potser fóra d'esperar ateses les equivalències del mot alemany a diccionaris de l'època com ara el de Tolhausen, ni per «fruits del bosc», com potser faríem actualment nosaltres per defugir el regust botànic o artificiós del terme baies. Riba tradueix aquest mot genèric per cireretes de pastor. Aquest és el cas, per exemple, del conte «Marienkind / L'infant de Maria». Hem de veure en aquest fet no pas un defecte de la traducció, sinó un fet de gran valor informatiu per a nosaltres, especialment pel que fa als hàbits alimentaris dels anys vint del segle passat als Països Catalans: en aquesta època i fora dels botànics, els fruits del bosc, com es diuen actualment, es menyspreaven. Llur aspror i acidesa els convertien en poc apreciats per a uns paladars malavesats amb tota la gamma de dolçors que els oferien els fruits conrats. El cas és relativament semblant al del ja vist Eichbaum/ Eiche: roure alzina, però no pas idèntic, perquè el roure es pot considerar un arbre molt conegut entre nosaltres, mentre que les baies, fa cent anys, només devien ésser conegudes entre els botànics. Per a Carles Riba, igual que per a la majoria dels seus compatriotes d'aleshores, l'única fruita del bosc que devia conèixer o que devia haver menjat era, precisament, la cirereta de pastor, i crec que degué ésser per això i pel fet apuntat adés que ell va adoptar i generalitzar aquest terme en la seva traducció com a equivalent català del mot Beere alemany, malgrat que, en l'adopció d'un terme concret, es perdia la inespecificitat del terme alemany.

Tanmateix, hi ha una excepció única i curiosa. Atès tot el que acabo de dir, a mi em sobta molt que Riba tradueixi el sintagma alemany rote Beeren, que apareix al conte «Schneeweisschen und Rosenrot / Blancaneu i Rosavermella», no pas per cireretes de pastor vermelles, com esperaríem, sinó per maduixes vermelles. Hi ha una infinitud de baies de color vermell i considero que, en la versió alemanya d'aquest passatge, el mot de color vermell només està ressaltant que, d'acord amb el seu designat, ens trobem davant un tipus de fruit que pertany a l'àmbit de la Rosavermella i no pas de la Blancaneu. Riba podria haver-se curat en salut ampliant la frase alemanya en català tot traduint el sintagma per «aplegant maduixes vermelles o altres fruits silvestres», però no ho fa i, si bé torna a donar-nos un concret català allà on en alemany hi tenim un genèric, aquest cop el mot emprat per ell és un terme diferent del terme habitual cireretes de pastor. Personalment, l'explicació que dono a aquest cas és que Riba possiblement no feia res més que adoptar la solució d'un traductor francès intermedi i que, per tant, la traducció que Riba ens dóna de l'alemany rote Beeren sammeln no és la seva solució sinó una solució que en realitat reflecteix 
un cueillir des fraises d'una traducció francesa consultada per ell. Un altre cas davant el qual no deixo de pensar que ens trobem amb un gal-licisme idèntic al presentat adés és un procedent del conte «Die Gänsehirtin am Brunnen / L'ocatera vora la font». En aquest conte hi apareix esmentada, en l'original alemany, la planta Moosrose, que Riba tradueix com a rosa molsuda. Davant la traducció ribiana, per bé que sigui impecable, no puc deixar de pensar que podríem trobar-nos davant una adaptació al català d'un terme francès, rose mousseuse o rose moussue, encara que no puc aportar cap prova en favor de la meva interpretació.

\subsection{Flora i fauna amb connotacions diferents en alemany i en català o amb un ús metafòric diferent}

En aquest apartat hi vull esmentar els casos de termes botànics i faunístics que tenen connotacions diferents en alemany i en català, així com termes botànics i faunístics emprats en alemany amb una càrrega metafòrica diferent.

En els casos que he detectat, Carles Riba no va entendre, si més no aparentment, l'original alemany. Així, en el conte «Hänsel und Gretel / Ton i Guida», la vella bruixa increpa la Guida dient-li oca toixa. Es tracta de la traducció de la locució alemanya dumme Gans (que té, al costat, el doblet blöde Gans). La traducció correcta hauria d'ésser tanoca, encara que, a Mallorca, es podria emprar l'equivalent annerota. Sigui com sigui, l'oca no ha tingut mai en català l'ús figurat de «persona estúpida». El mateix cas es repeteix a «Aschenputtel / La Cendrosa», on les germanastres insulten la pobra Ventafocs dient-li oca taujana, és a dir, dumme Gans.

Un altre cas és el format per l'expressió alemanya wunderlicher Kauz, amb el doblet modern, komischer Kauz. Riba tradueix el sintagma com a fantàstic mussol («Der Eisenhans / Janferrís»). El mot alemany serveix, però, per designar un tipus estrany o estrafolari.

Un darrer exemple procedeix del conte «Schneeweißchen und Rosenrot / Blancaneu i Rosavermella». En el text alemany hi llegim «Ist das Manier, ihr Lorche, einem das Gesicht zu schänden?», que Riba tradueix com a «Això és manera, llonzes, de desparençar la meva cara?». En el text alemany ens trobem davant una designació del gripau pròpia del nord d'Alemanya (Lorch), que, en sentit figurat, s'empra com a designació pejorativa d'una dona o noia com a «spottname für eine kleine unansehnliche person» (Grimm, Wörterbuch, sub voce Lurch) és a dir, «persona petita i insignificant». En el text català, en canvi, ens trobem davant un adjectiu substantivat, llonze, que només significa beneit. És possible que Riba el triés per la ressemblança fonètica amb el mot alemany. Tanmateix, indico que en el Diccionari català-valencià-balear hi trobem que el català gripau té, en sentit figurat, el significat de 'beneit, ximple', de manera que 
Riba, si aquest ús figurat li resultava conegut, hauria pogut triar aquest mot - gripau - per comptes del llonze que va triar.

Així, doncs, el mot gripau/Lorch/Lurch admet un ús metafòric en una llengua i l'altra, però l'ús figurat no és coincident: en alemany del nord hi és una designació despectiva de dones i noies caracteritzant-les com a bestioles insignificants; en català, en canvi, el mot designa, usat figuradament, una dona estúpida o bé una dona llorda i, sobretot, una dona lletja. El diccionari Tolhausen tradueix correctament el mot Lorch per sapo, escuerzo. Si Riba disposava d'aquest diccionari — i estic segur que ho feia-, hauria pogut traduir el mot alemany per gripau. Personalment, però, crec que Riba aquí o bé es va guiar directament per alguna traducció francesa que interpretava el plural alemany Lorche en el sentit de beneites, estúpides o bé es va deixar guiar per la seva intuïció i va considerar que aquest significat esqueia prou bé al mot en el context en qüestió. En aquest mateix conte, per cert, hi apareixen altres locucions, usades en sentit figurat, que Riba tampoc no acaba de copsar correctament: així, el nan del conte hi tracta les dues germanes de wahnsinnige Schafsköpfe, que en sentit figurat significa 'bàmboles boges' i en sentit literal, 'caps de be boges' i que Riba tradueix com a caps de be, eixelebrades. Poc després el nan insulta les dues noies dient-los ungehobeltes Volk, és a dir, 'toixarrudes, mancades de bones maneres', que Riba tradueix literalment com a gent per desbastar. Personalment, no donaria pas la culpa a Riba d'aquestes males traduccions, sinó exclusivament a la mala qualitat dels diccionaris bilingües d'aquells temps, que sovint descuraven l'ús figurat dels mots, especialment en l'àmbit col·loquial.

La persona que comença a aprendre una llengua, així com la persona que tradueix (professionalment o no), necessita disposar de bons diccionaris, ja que depèn dels diccionaris. El diccionari és un veritable mitjancer lingüístic, un transmissor de la llengua. Si el diccionari és dolent, aquest fet repercuteix en la feina del traductor i en la qualitat de la llengua que s'ha après a través de la informació aportada pel diccionari en qüestió. És impossible que algú tingui dins el seu cap tot el cabal lèxic d'una llengua. D'aquí ve que sigui importantíssim que els diccionaris siguin bons i una bona part de la qualitat d'un diccionari ve donada pel fet que el seu autor o autors han sabut contemplar la riquesa d'usos que pot arribar a tenir un mot en la llengua A del diccionari. Dic això perquè atribueixo certs errors de Riba als diccionaris que feia anar i no pas directament a ell mateix. Un d'aquests errors el tenim al conte de la «Rapunzel/Repunxó». En aquest conte se'ns relata així l'intent de suïcidi del príncep, saltant daltabaix de la torre: «Der Königssohn geriet außer sich vor Schmerz, und in der Verzweiflung sprang er den Turm herab: das Leben brachte er davon, aber die Dornen, in die er fiel, zerstachen ihm die Augen». Riba tradueix: «El fill del rei, de la pena, perdé el món de vista, i en la seva desesperació saltà 
daltabaix de la torre; se'n va aixecar amb vida, però les espines damunt les quals caigué, li foradaren els ulls».

Riba tradueix aquí el plural die Dornen per «les espines». En principi la traducció fóra correcta, és el que hi posa als diccionaris, però die Dornen no vol dir aquí les espines, sinó els arbustos espinosos, els espinars (el plural die Dornen és sinònim de Dornbusche o Dornensträucher) i aquests arbustos espinosos són, en primera línia, el Weißdorn (cirerer de pastor, arç blanc) o el Hagebuttenstrauch (gavarrera). Una consulta del diccionari Tolhausen, que Riba devia utilitzar, ens confirma que només dóna l'equivalència espina al mot alemany Dorn.

En aquest mateix sentit es pot esmentar també la traducció del conte «Der Jude im Dorn / El jueu dins la bardissa». En aquest conte, constatem una divergència en la traducció del mot Dorn en el títol i a l'interior del conte: mentre que Riba tradueix el títol correctament com a bardissa, a l'interior del conte hi trobem l'antiga equivalència Dorn:espina. L'explicació que hi dono és que algú devia fer notar a Carles Riba que Dorn no solament és espina en alemany, sinó també espinar, i Riba va corregir el títol del mot d'acord amb aquesta indicació, però en canvi no devia recordar - o potser no els va pas trobar- els passatges de l'interior del conte on es donava l'antiga equivalència Dorn:espina i que també calia corregir.

En aquest mateix conte hi apareixen dos mots més que Riba tradueix d'una manera que podem qualificar de no correcta. En primer lloc, tenim el mot Busch, en singular, que Riba tradueix com a mates. És un dels pocs indrets on la intuïció lingüística va fallar a Carles Riba. El diccionari Tolhausen dóna tres traduccions possibles del mot alemany Busch: I) mata, 2) arbusto i 3) soto, espinar. En el context del conte, Busch és clarament bardissa, no mates. És, per tant, sinònim de Dornbusch. Potser si Riba hi hagués afegit un adjectiu com ara «espinoses» no sobtaria tant al lector català que el jueu del conte es fiqui sota unes mates i que després es punxi amb les espines d'aquestes mates. Les mates nostres no tenen pas espines. El lector català, perquè la traducció hagués estat correcta del tot, hauria d'entendre, en llegir el conte, que el jueu s'ha ficat dins una bardissa d'arços blancs - no pas d'esbarzers-. L'arç blanc o cirerer de pastor és, per cert, una de les plantes amb més presència, directa o indirecta, als contes dels germans Grimm. 
3. La traducció de Riba com a exemple de traducció mitjançada o traducció mixta a través dels termes botànics/faunístics emprats

Atesa la meva experiència en aquest camp, goso afirmar que, en el moment que Carles Riba va dur a terme la seva traducció dels contes dels germans Grimm, especialment la dels anys I9I9-I92I, el seu coneixement de l'alemany només devia ésser rudimentari. Efectivament, el fet que Carles Riba, com ens fa avinent l'erudit i estudiós de Riba Jaume Medina, hagués estudiat l'alemany en el batxillerat, no és suficient per afirmar el contrari.

L'estada d'un any a Alemanya, a més a més, atès que es va dur a terme en un ambient de romanistes a la universitat i, a més a més, transcorregué per a Riba en un ambient familiar catalanoparlant a casa (Riba va anar a Múnic amb la seva dona), fa pensar que, si bé hi pogué millorar en gran manera el seu coneixement de l'idioma alemany, aquesta millora no fou suficient com per dominar-lo amb la profunditat que l'activitat de la traducció directa alemany-català exigeix o requereix.

L'alemany del batxillerat i el fet que gaudís d'una beca del Consell de Pedagogia de la Mancomunitat per estudiar filologia romànica i estilística durant un any, del $1922^{4}$ al 1923 , a la Universitat de Munic amb el professor Karl Vossler, per tant, no es poden pas considerar criteris determinants per postular que Riba dominava bé l'alemany a finals dels anys deu del segle passat.

No vull que se'm malentengui: no jutjo pas la qualitat de les traduccions ni la mateixa activitat de la traducció duta a terme per Carles Riba, sinó únicament si aquest tenia o no prou coneixements d'alemany per fer-la des de l'original alemany. Uns cursos d'alemany fets a Barcelona, amb una metodologia que copiava la metodologia d'aprenentatge del grec i el llatí i es basava, per tant, en la traducció de textos literaris, i uns mesos a Munic no donen espai per a uns coneixements gaire profunds de la llengua.

Per tot això afirmo que Carles Riba no va traduir directament els contes de l'alemany, sinó que els va traduir en el marc d'un procediment que trobem sovint darrere l'activitat de molts de traductors de l'alemany i altres llengües al català i que en podem anomenar traducció mitjançada o, si es vol, traducció guiada, un tipus de traducció mixt directe-indirecte que, bàsicament, consisteix que la traducció es fa des de l'original però tenint al costat una traducció del text original a una llengua que hom

4. Cf. Medina (I989: 50-5I): «Però la gran passió dels Riba eren els viatges: a finals del I92I el poeta va rebre la nova que el Consell de Pedagogia de la Mancomunitat li concedia una pensió per anar a Alemanya a ampliar els seus estudis. La família Riba partia cap a aquell [p. 5I] país a principis de març del 1922 i va restar-hi tot un any» (és a dir, fins a primers de març del I923). A les pàgines següents, Medina transmet una bona informació de conjunt de tota l'estada de Riba a Alemanya. 
coneix bé i que, en el cas de molts de traductors catalans, fou, tradicionalment i fins a la dècada dels anys vuitanta del segle passat, una traducció francesa. Aquesta traducció intermèdia existent entre el text original i el text final català el traductor o la traductora l'empra com a traducció-guia o text-crossa: això vol dir que, en el procés de la traducció, el text original s'utilitza sempre, però tots o, si més no, molts dels problemes translaticis reals que poden sorgir-li al traductor en el procés de la traducció són resolts partint de la solució oferta per la traducció mitjancera o intermèdia i no pas a partir de criteris propis basats en l'experiència o en la consulta d'obres alemanyes i especialistes nadius o nadius a seques.

Si aquesta anàlisi és encertada, els contes dels germans Grimm en català tenen, en realitat, com a mínim, dos originals: un d'alemany i un de francès. Ja he esmentat a dalt el cas de la traducció de l'alemany rote Beeren sammeln com a plegar maduixes i que pot representar un francès cueillir des fraises. Ara voldria il-lustrar el que he dit amb el cas Drossel-griva-tord. Riba tradueix el conte «König Drosselbart» com a «El rei Barba-de-griva». Aquí som davant un terme alemany, Drossel, que en aquesta llengua és un genèric $i$, com a tal, li correspondria també en català un genèric que hauria de ser forçosament el mot tord; en canvi, en francès, el genèric per designar els diferents ocells del gènere Turdus i de la família dels túrdids és grive. La griva catalana, per contra, és un ocell molt específic, en concret, és la designació de l'espècie Turdus viscivorus, que en alemany es diu Misteldrossel i grive draine en francès. El fet que Riba tradueixi Drosselbart com a Barba-de-griva i no pas com a *Barba-de-tord apunta cap a una traducció del mot alemany a través del francès, ço és, darrere l'expressió «rei Barba-de-griva» no hi ha, per tant, el König Drosselbart alemany, sinó un text intermedi francès que devia sonar «le roi Barbe-de-Grive».

Un altre exemple podria esmentar-se en algun tret sintàctic. Al conte «Die zwei Brüder / Els dos germans», hi llegim la frase «Senyor hostaler, ara ja he menjat i begut del mateix que el rei menja i beu», amb un típic genitiu partitiu francès. La frase alemanya corresponent fa: «Herr Wirt, nun hab ich gegessen und getrunken, wie der König ißt und trinkt», sense cap construcció que pogués haver servit de guia al genitiu partitiu català.

\section{Els diccionaris bilingües de què disposava Riba i la nomen- clatura faunística i botànica}

Una altra variable desconeguda que cal tenir en compte, com ja he esmentat a l'inici del present treball, és la constituïda per les obres lexicogràfiques bilingües de què Riba disposava i que va utilitzar en la seva traducció, perquè aquestes obres lexicogràfiques havien de condicionar per força la traducció dels noms d'animals i plantes de l'alemany al català. Des d'aquesta perspectiva, el mot triat per Riba és el mot ofert pel seu diccionari de consulta, quan no tenia una coneixença pròpia del mot 
alemany. L'accés a la terminologia botànica, faunística i cultural de l'alemany Riba la va fer a través del francès, d'una banda, i a través de les obres lexicogràfiques bilingües alemany-castellà i alemany-català existents en aquells moments.

Igual que en el punt anterior, només una consulta de l'Arxiu Riba pot fer il-luminar de manera definitiva aquest punt. Tanmateix, valguin els mots següents: a finals dels anys vint del segle passat, la millor obra lexicogràfica bilingüe alemany-castellà/castellà-alemany que existia era, sens cap mena de dubte, el diccionari de Louis Tolhausen: Neues spanischdeutsches und deutsch-spanisches Wörterbuch, publicat a Leipzig a l'editorial Bernhard Tauchnitz, i existent en nombroses edicions des del I888I889, la data de la seva primera aparició. A finals dels anys vint, i després de la fallida de l'editorial Tauchnitz, aquesta obra fou adquirida per l'editorial Herder, la qual, després d'haver-la feta revisar per Rudolf Jan Slabý i Rudolf Grossmann, la tornà a publicar el 1932 (alemany-castellà) i el I937 (castellà-alemany) amb el nom amb què hom la coneix actualment: l'Slabý-Grossmann.

També cal esmentar el diccionari, en dos volums, de Theodor Stromer, Nuevo diccionario español-alemán [y alemán-español] con arreglo al diccionario de la Real Academia Española / Neues spanisch-deutsches und deutsch-spanisches Wörterbuch, auf Grund des Wörterbuchs der Königlichen Spanischen Akademie (Berlín: F. A. Herbig \& Alb. Sayffaerth, I897 i I90o).

Amb posterioritat a la data de publicació dels contes dels germans Grimm, cal esmentar els diccionaris d'Ernest Pfohl, Neues Wörterbuch der spanischen und deutschen Sprache für den Schul- und Handgebrauch (2 volums. Leipzig: 193I) i el ja esmentat Slabý-Grossmann, basat àmpliament en el diccionari de Tolhausen. Cal esmentar aquests diccionaris perquè, si més no hipotèticament, Riba els pogué haver utilitzat en la traducció dels contes de Grimm del I935 que fou publicada per l'editorial Joventut.

Quant al català, ignoro fins a quin punt Carles Riba disposava del diccionari Taschenwörterbuch der katalanischen und deutschen Sprache, d'Eberhard Vogel, publicat a Berlín el I9II (català-alemany) i el I9ı6 (alemanycatalà) per l'editorial Langenscheidt, i que enceta l'activitat lexicogràfica bilingüe moderna en l'àmbit català-alemany. Conec personalment aquest diccionari i puc dir que, encara que ja hagin passat cent anys d'ençà de la seva publicació, continua essent un diccionari molt bo.

En aquest sentit, voldria esmentar el cas del conte «Der Zaunkönig und der Bär / El reietó i l'ós». Deixem de banda de moment la traducció dels mots Bär i Wolf (animals que apareixen en aquest conte i als quals tornaré adés) i concentrem-nos en la traducció del mot Zaunkönig. Zaunkönig és la designació estàndard alemanya de l'ocell catalogat taxonòmicament com a Troglodytes troglodytes Lennaeus. La designació catalana del Troglodytes troglodytes és caragolet (amb la variant cargolet); passaforadí, un mot em- 
prat a les Balears, i sageta. ${ }^{5}$ El DCVB dóna, com a equivalent científic del català cargolet, el tàxon Troglodytes parvulus Koch. No es tracta d'un ocell diferent, sinó de la designació taxonòmica proposada per l'alemany Carl Ludwig Koch, mentre que la que s'ha imposat actualment és la del suec Carl von Linné.

Carles Riba tradueix aquest mot Zaunkönig no pas per caragolet o cargolet, com fóra correcte i esperable, sinó per reietó. Les raons per les quals ho fa poden ser múltiples: per exemple, perquè el text francès que devia tenir havia traduït el terme alemany amb el francès roitelet «reietó», o bé per poder fer un joc de paraules en català entre rei i reietó idèntic o paral.lel al joc de paraules existent en alemany entre König «rei» i Zaunkönig, ${ }^{6}$ que vol dir «rei de les tanques», però també, i simplement, perquè el diccionari de què Riba disposava donava [erròniament] com a equivalent de l'alemany Zaunkönig el terme reyezuelo. El diccionari Tolhausen dóna realment com a equivalent de Zaunkönig el castella reyezuelo, mentre que el terme que en castellà designa realment aquest ocell, el chochín, hi figura com a equivalent de l'alemany Schnepfe (Waldschnepfe, Scolopax rusticola, chocha o becada en castellà i becada en català). Com que no em consta que Carles Riba expliqués enlloc per què va triar el mot català reietó per al Zaunkönig alemany, només podem especular sobre aquest tema, però el fet que el millor diccionari d'aquell temps, el diccionari Tolhausen, donava reyezuelo (i, per tant, es pot dir que també reietó) com a equivalent de l'alemany Zaunkönig pot haver estat la causa o pot haver-hi influït ${ }^{7}$ perquè Riba triés aquest mot i no pas el mot caragolet.

\section{Un cas especial: Rapunzel/Repunxó}

El títol d'aquest conte fa referència a la seva protagonista, la qual es diu d'aquesta manera per una planta que sa mare menja amb fruïció quan n'està embarassada.

En alemany, Rapunzel és la designació meridional d'un tipus d'amanida a la qual en català designem amb el nom de canonges o herba de canonges. La designació científica de la planta és Valerianella locusta L. Carles Riba li dóna l'equivalència catalana de repunxó. Un cop d'ull a l'Enciclopèdia Larousse en català ens indica que el nom botànic repunxó és una «herba biennal de la classe de les magnoliates, de la subclasse de les as-

5. Cf. Saval: 5 sub vocibus caragolet i sageta. DIEC 1995: 349 (caragolet) i II28 (sageta). Ni Saval ni DIEC donen entrada al baleàric passaforadí.

6. Obviant que, en el cas alemany, no solament ens trobem davant un joc de paraules entre König i Zaunkönig, sinó també davant de tot un simbologisme popular existent al voltant del caragolet que no es dóna pas en el reietó. L'ocell en qüestió és un ocell de la bona sort i de l'hivern (com a Mallorca l'oroneta ho és, per exemple de la bona sort i l'estiu) que representa la grandària interior en un cos petit.

7. Cf. Tolhausen (I889: 80I). 
tèrides i de la família de les campanulàcies (Campanula rapunculus), més o menys pubescent, de fulles oblongues o estretament lanceolades, flors blaves disposades en raïm i fruit en càpsula. Creix als marges del bosc i als herbassars, en indrets més o menys humits». ${ }^{8}$ L'enciclopèdia no ens fa avinent si aquesta planta és conrada o no, ni ens dóna notícia sobre si és comestible o no. A la reedició del I986 dels Contes, es va considerar oportú afegir una nota a peu de plana que explica el mot repunxó. La nota diu «Repunxó: planta herbàcia de flors acampanades blaves en panícula estreta i arrel carnosa fusiforme», és a dir, identifica totalment la planta amb la Campanula rapunculus. ${ }^{9}$

Una visita a l'Herbari Virtual del Mediterrani Occidental, antigament Herbari Virtual dels Països Catalans, ens en proporciona diverses imatges i més informació, encara que tampoc no ens informa dels dos detalls essencials esmentats adés: si es conra i si és comestible. ${ }^{\text {Io }}$

Amb la visita a un altre herbari virtual, com és ara Den virtuella floran, ${ }^{\mathrm{II}}$ se'ns hi diu específicament que la planta és comestible i que, antigament, la seva arrel s'emprava com a verdura: «Användning. Rapunkelklockans rot är ätlig och arten odlades förr som köksväxt. Enligt Nyman (I868) är roten 'närande samt smakar nästan som Scorzonera'» [L'arrel del repunxó és comestible i l'espècie s'emprava antigament com a verdura. Segons Nyman (I868) la seva arrel és «nutritiva i de gust gairebé idèntic al de l'escurçonera o Scorzonera hispanica»]. ${ }^{\mathrm{I}}$

Heinrich Marzell, al seu monumental Wörterbuch der deutschen Pflanzennamen, ens informa que en el món alemany només se n'aprofitava l'arrel. Viquipèdia, ${ }^{\mathrm{I}}{ }^{\mathrm{s}}$ si la informació que ens proporciona és la correcta, ens informa que antigament es conrava «com a hortalissa a Europa» $\mathrm{i}$ apunta que també se'n menjaven les fulles, si més no a certs indrets. En tot cas, el repunxó, la Campanula rampunculus L, als Països Catalans sembla que sempre hi ha estat una planta silvestre i que la part aprofitable, si és que mai s'hi ha arribat a consumir — cosa que jo personalment dubto-, aparentment s'havia limitat a l'arrel, no pas les fulles. Però si mirem cap al conte de la Repunxó hi llegim coses que no s'adiuen pas a aquestes dues característiques: «Un dia, la dona s'estava en aquesta finestra guaitant a l'hort i reparà un bancal plantat d'uns repunxons que enamoraven. Tan frescos i tan verds apareixien que li'n vingué desig: li agafà la dèria més gran d'aquest món de menjar-ne. [...] L'home s'espantà i preguntà: -Què tens, esposa? —Ah — respongué ella—. Si no aconsegueixo de menjar un repunxó [en alemany en plural: "keine Rapunzeln"] de l'hort de sota casa,

8. Cf. Larousse 9 (Rampal-Sulfúric): 4I8I.

9. Pàgina 40.

Io. <http://herbarivirtual.uib.es/cat-med/especie/6463.html>.

II. <http://linnaeus.nrm.se/flora/di/campanula/campa/camprus.html>.

I2. Traducció de l'autor.

I3. <http://ca.wikipedia.org/wiki/Repunx\%C3\%B3>. 
jo em moriré. L'home que l'estimava pensà: “Abans de deixar morir la meva dona, vés a cercar-li un repunxó [en alemany en plural: "Rapunzeln"], costi el que costi". A l'entrada de fosc s'enfilà dalt la paret, saltà a l'hort de l'encisera, collí a corre-cuita un manat de repunxons i els portà a la seva dona. Ella se'n va fer un amanit, i se'ls menjà amb tot l'afany d'aquest món.»

Aquest passatge hauria de deixar astorat el lector català modern per dues raons: I) constataria que els repunxons es mengen, i 2) que també en conren, o, si ens ho estimem més, que es menjaven i que es conraven. En tot cas, el passatge esmentat ens revela tres dades significatives sobre la planta alemanya i una sobre el coneixement que en tenia Riba. La informació que rebem sobre la planta en l'entorn alemany és que: I) és una planta que es conra; 2) és una planta les fulles de la qual es mengen, i 3) és una planta que es menja crua: en concret, se'n mengen les fulles i tiges com a amanida. La dada que la traducció catalana del passatge ens revela és que Riba no sabia què eren els repunxons perquè, si ho hagués sabut, hauria traduït sempre el plural alemany per un plural català — cosa que no fa- . Aparentment, Riba devia creure que els Rapunzeln alemanys devien ser com a raves o cols; en tot cas, una cosa que en el seu temps es devia comprar per unitats.

Com ja he dit a dalt, el nom d'aquesta planta és la designació, pròpia del sud d'Alemanya, de la Valerianella locusta L. Al centre i nord d'Alemanya la planta se sol designar amb el terme Feldsalat..$^{14}$ Aquesta planta, segons l'Herbari Virtual de la Mediterrània Occidental, no es dóna als Països Catalans de forma autòctona. La seva presència a les botigues i als restaurants moderns s'ha d'entendre, per tant, com a fruit de la globalització alimentària que vivim, possiblement com a efecte de la cuina francesa, ja que aquesta mena d'amanida sí que té a França una llarga tradició de consum humà i ús gastronòmic. El nom català amb què hom la coneix, herba dels canonges o, simplement, canonges, possiblement només és una adaptació del francès herbe des chanoines que ens hagi arribat per via del castellà hierba de canónigos o canónigos. En francès estàndard es designa habitualment amb el mot mâche, rampon ${ }^{15}$ i raiponce, que són designacions idèntiques a la del sud d'Alemanya. Segons tot això: fóra més que possible que Riba hagués donat el nom de Repunxó a la protagonista del conte a partir d'una traducció francesa que, al seu torn, hagués posat el nom de Raiponce a la protagonista.

\footnotetext{
I4. Cf. <http://linnaeus.nrm.se/flora/di/valeriana/valel/valeloc.html>, $<$ http://fr.wikipedia.org/wiki/Valerianella_locusta , $<$ http://de.wikipedia.org/wiki/Gew\%C3\%B6hnlicher_Feldsalat $>$.

I5. Cf. <http://www.jardin.ch/info/rampon.html $>$.
} 


\subsection{Rapunzel i les seves connotacions}

És obvi que la traducció de Rapunzel per Repunxó sempre s'ha de veure com a millor que no pas per un mot com ara Canonges. Una protagonista del conte que es digués Canonges faria riure els eventuals oients i lectors del conte, un efecte que cal evitar en un conte que no té gaire comicitat i sí, en canvi, una gran càrrega tràgica. D'altra banda, la realitat és que, en una societat desruralitzada que ha desaprès la terminologia botànica i faunística, un terme com ara Repunxó no té cap mena de connotació i, per a la immensa majoria dels parlants, tampoc no denota res. Però si no haguéssim donat l'esquena al món rural i si encara coneguéssim la terminologia botànica, possiblement ens sobtaria molt llegir que una fetillera alemanya tenia bancals d'una planta silvestre de la qual aquí només es menjaven les arrels i que una senyora s'enamora de les seves fulles i se les menja. Alguna cosa no quadra. I aquesta constatació s'agreujaria encara més si gratéssim una mica en el mot alemany, car aleshores descobriríem coses com ara que:

A banda del fet que el nom designa al sud del territori lingüístic alemany la planta Valerianella locusta L., la veritat és que el mot s'assembla moltíssim a Punze, un mot que al sud d'Alemanya vol dir o volia dir 'vulva', i a Punzl, el seu corresponent diminutiu: 'conyet'. Aquesta semblança no pot ser fortuita al meu entendre. Tinc per a mi que el nom alemany de la noia es va triar a posta perquè pogués servir per designar-hi en el conte l'arquetip femení per antonomàsia, caracteritzat pels trets exteriors del seu sexe: la vulva. És com si a la noia l'haguessin batejada «La Dona», però recorrent a un terme de clares referències sexuals. Crec oportú indicar aquí que, si més no en castellà, una designació despectiva — però alhora usual-de noies i dones és, precisament, los coños.

Davant aquest fet, caldria fer-nos la pregunta si la traducció al català del nom de la protagonista és possible o si, més aviat, no caldria recórrer a una adaptació. La utilització d'aquest terme botànic - Rapunzel- juntament amb altres fets que apareixen al llarg del conte em fan pensar que aquest conte no té res de popular, excepte que fou escrit pensant en un destinatari ideal popular i que cal cercar el seu origen últim a la baixa edat mitjana: fa olor pels quatre costats d'eiximpli o apòleg medieval, de composició literària composta per ser llegida com a constituent d'algun llibre edificant o per ser declamada per un predicador en el marc d'un sermó religiós. I el tema real del conte, aparentment si més no, és el de l'incest entre germans.

Fixem-nos en narracions semblants on surt una filla que arriba a la pubertat i una torre on és tancada o on se l'ha de tancar: són narracions que giren al voltant de l'incest per bé que no pas entre germans - com fóra el nostre conte-, sinó entre pare i filla. Mirem el cas, per exemple, de la història de santa Bàrbara, de qui s'enamora son pare, i, gelós del contacte de sa filla amb qualsevol home, ordena que li construeixin una torre i que 
hi tanquin sa filla a dins: només ell ha de poder tenir-hi accés. Fora del llegendari cristià també trobem el mite de l'incest escenificat al voltant d'una torre, per exemple, en el mite d'Acrisi, Dànae i Perseu. Els poetes llatins Horaci i Ovidi ens conten una variant del mite en la qual la filla d'Acrisi, Dànae, és tancada dins una torre ${ }^{16} \mathrm{i}$ que és dins aquesta torre on rep la visita de Zeus transmutat en raig d'or. ${ }^{17}$ En el mite original grec, en canvi, l'Acrisi ${ }^{18}$ havia tancat la Dànae dins una cambra de bronze hermètica subterrània: una torre, d'alguna manera, per més que subterrània. Cal esmentar el mite de Dànae no solament perquè en la versió llatina l'avi fa construir una torre dins la qual tancarà la seva néta, sinó també perquè el

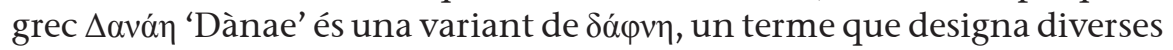
plantes, entre elles el verinós llorer. $^{19}$

A banda de la llegenda de santa Bàrbara i del mite d'Acrisi, Dànae i Zeus, vull encara esmentar un tercer constituent possiblement afaiçonador del conte: el de la història de Veleda, la profetessa brúctera verge que també «habitava en una alta torre», segons ens informa el Tàcit, i a la qual cap home no podia pas accedir, ni tan sols els delegats romans de Colònia quan li portaren regals.

Si interpretem el conte com un apòleg cristià contra l'incest entre germans, la torre es converteix en realitat en la cuirassa que la mare-bruixa de la noia (és a dir, la mare i la bruixa són la mateixa persona vista des de dos angles diferents per la filla que ha arribat a la pubertat) imposa a la seva filla per protegir-la dels patiments del llaç afectiu amb el germà. La torre és la llar paternomaternal de la qual la Repunxó no pot fugir i en la qual ha d'estar protegida d'un contacte massa estret amb el seu germà. Si a santa Bàrbara tenim tematitzat i tractat l'incest entre pare i filla, en el conte de la Repunxó tindríem tematitzat l'incest entre germà i germana.

La torre, la cuirassa protectora al voltant de la filla, al final no és efectiva i es produeix l'embaràs de la Repunxó. L'embaràs és un resultat de l'incest de greus conseqüències en el conte, però conseqüències que recorden les d'infinitud de relats hagiogràfics o pseudohagiogràfics de temàtica semblant com ara la del relat del doble incest germà-germana i mare-fill que trobem al Gregòrius medieval encadenat a la roca.

I6. Cf. Horaci, Odes, III, I6, I-4. Ovidi, Art d'amar, III, 4I5-4I5.

I7. Vet ací l'origen últim de la cabellera daurada: és el raig d'or que arriba del cel fins a la noia i que l'embarassarà. En el reafaiçonament apologètic del mite, aquest raig espermàtic no lliga la noia al cel —com en el mite grecollatí-, sinó a la terra.

I8. Vull esmentar aquí que a la darrera versió cinematogràfica del mite que conec, estrenada el 2010 amb el títol Xoc de Titans (títol original: Clash of the Titans), Acrisi hi és convertit en marit de Dànae. D'aquesta manera els guionistes resolen, al meu entendre, la càrrega incestuosa latent existent entre pare i filla en el mite original.

I9. Curiosament, la Viquipèdia <http://ca.wikipedia.org/wiki/Llorer\#Usos_medicinals> ens informa que el llorer/Dànae és un «regulador de la menstruació», que s’ha emprat «com a remei que provoca l'evacuació menstrual de les dones» i que «és recomanat abstenir-se de prescriure olis essencials per via interna durant l'embaràs». 
La conseqüència de l'incest, tant en el conte com en altres moltes narracions, és la ceguesa de l'home i la seva proscripció, que serveixen perquè comenci una vida de penitència a la recerca del perdó diví. La Repunxó que queda embarassada del seu amant, que és el seu germà, també és desterrada i també ho és com a inici d'una vida de penitència que ella farà juntament amb els dos bessons que té, un nen i una nena, i que il.lustren la unió perfecta, absolutament igual, de germà i germana.

Ell i ella no poden tornar a sucumbir a la temptació. Per això la penitència d'ella es fa al desert, mentre que la d'ell té lloc al bosc. En la traducció de Riba, llegim de l'anònim protagonista masculí que «vagarejava trist pel bosc, només menjava herbes i arrels i no parava de plorar».

Quan el perdó diví finalment es produeix, anys més tard, el cec va a parar sense saber ben bé com al desert on vivia en la misèria la Repunxó amb els seus fills. La veu d'ella li resultà familiar, i ella també el va reconèixer i se li va tirar al coll. El perdó de Déu es fa palès en el moment en què ell, banyat per les llàgrimes d'ella, recobra la vista. És aquí on, versemblantment, devia acabar l'apòleg originari. El final feliç de la parella casant-se i anant-se a viure al regne d'ell és un final grimmià, però no pas l'original. El conte, com ja he dit, no té res de popular, sinó de totalment erudit. El seu autor, fos qui fos, coneixia la història (la torre on vivia la verge Veleda, protegida així dels homes), coneixia la mitologia (Horaci i Ovidi) i coneixia la llegenda de santa Bàrbara.

Personalment, estic convençut que l'origen de la Rapunzel es trobarà recercant en la literatura homilètica i d'apòlegs alemanya de la baixa edat mitjana i Renaixement.

\section{Conclusions}

Les conclusions del meu treball són diverses.

Per a la filologia alemanya, l'estudi de la flora i la fauna dels contes pot emprar-se com a factor indicatiu de llur origen geogràfic, de la data de llur origen i de si l'origen s'ha de cercar en un entorn culte, rural o urbà. La fauna i la flora de l'estrat rondallístic més antic no contempla la presència d'exoanimals i exoplantes, és a dir, animals i plantes pertanyents a espècies no alemanyes. Allà on surten aquests animals podem trobar-nos davant un conte originàriament no alemany.

Per a la filologia catalana, l'estudi de la fauna i la flora ens serveix per desentrellar una mica la forma de treballar de Riba i les obres de què, possiblement, disposava per a la seva feina.

Carles Riba va haver de solucionar un seguit de problemes derivats de la manca d'obres lexicogràfiques bilingües i la manca d'un estàndard consolidat. La traducció dels Contes dels germans Grimm, a més a més de servir-li per a l'aprenentatge de l'alemany, també li va servir d'exercici 
estilístic del català, al qual va enriquir avesant-lo a l'ús d'un seguit de termes botànics i faunístics, l'estudi exhaustiu del qual només es pot fer en el marc d'un projecte major.

\section{Bibliografia}

Avibase <http://avibase.bsc-eoc.org/species.jsp?lang=CA\&id=76Di888D $\mathrm{I} 2 \mathrm{E} 3406 \mathrm{~F} \& \mathrm{ts}=\mathrm{I} 2 \mathrm{I} 559725 \mathrm{I} 562 \& \mathrm{sec}=$ summary $>$ [data de consulta: desembre de 20I2].

BIBILONI, Gabriel: Vocabulari del Cavall <http://bibiloni.cat/cavall.htm> [data de consulta: desembre de 20I2].

Fauna Europaea <http://www.faunaeur.org/full_results.php?id=I678I6> [data de consulta: desembre de 20I2].

LuTHer, D. Martin (I974): Die gantze Heilige Schrifft. Munic: DTV TextBibliothek.

MARzELl, Klaus (2000): Wörterbuch der deutschen Pflanzennamen, Band I-V. Colònia: Parkland.

Medina i CASANOvas, Jaume (I989): Carles Riba (1893-1959). Barcelona: Publicacions de l'Abadia de Montserrat.

- (2000): Estudis Sobre Carles Riba. Barcelona: Publicacions de l'Abadia de Montserrat.

- (2007): «Carles Riba i Alemanya». Dins: Arnau PONS; Simona ŠKRABEC (cur.). Carrers de frontera: passatges de la cultura alemanya a la cultura catalana. Vol. I. Barcelona: Institut Ramon Llull, p. I74-I8I.

Miralles, Carles (I999): «Les traduccions de Riba a la "Biblioteca Literària"». Dins Homenatge a Arthur Terry. Vol. II. Barcelona: Publicacions de l'Abadia de Montserrat, p. 243-250.

Tolhausen, Luis (I889): Nuevo Diccionario Español-Alemán y AlemánEspañol/Neues spanisch-deutsches und deutsch-spanisches Wörterbuch. Zweiter Band: Deutsch-Spanisch. Leipzig: Bernhard Tauchnitz.

VielHAUER, Inge (I979): Bruder und Schwester: Untersuchungen und Betrachtungen zu einem Urmotiv zwischenmenschlicher Beziehung. Bouvier. 